\title{
Study of suitability of AvaSpec array spectrometer for solar UV field measurements
}

\author{
I. Ansko ${ }^{1,2}$, K. Eerme ${ }^{1}$, S. Lätt ${ }^{1,2}$, M. Noorma ${ }^{2}$, and U. Veismann ${ }^{1}$ \\ ${ }^{1}$ Tartu Observatory, 61602, Tõravere, Estonia \\ ${ }^{2}$ Tartu University, Ülikooli 18, 50090, Tartu, Estonia
}

Received: 4 December 2007 - Published in Atmos. Chem. Phys. Discuss.: 29 February 2008

Revised: 15 May 2008 - Accepted: 23 May 2008 - Published: 27 June 2008

\begin{abstract}
A system to record the ultraviolet (UV) spectra of atmospheric global irradiance with the miniature fiber optic spectrometer AvaSpec-256 was developed for continuous computer-aided spectrometry at Tartu Observatory in 2005. As a result, the database of spectra recorded with 15-mininterval round $24 \mathrm{~h}$ over $300-400 \mathrm{~nm}$, has been developed. The quantities retrieved from the spectra have been compared with those measured by the Scintec erythemal UV-SET sensor and the Kipp \& Zonen narrowband $306 \mathrm{~nm}$ sensor. Almost clear and overcast days were selected for comparison. Reliable results on the spectral distribution of the UV global irradiance as well as the integrated daily spectral doses could be obtained at least during the bright half-year. The results were compared with the calculations performed by means of the LibRadtran package. The biases in irradiance were significant at SZA above $70-75^{\circ}$. At dominating larger SZA the recorded values need sophisticated corrections and remain less reliable. At lower latitudes than that of the study site $\left(58.3^{\circ}\right)$, the reliability of the spectrometer is expected to increase due to a smaller contribution of data measured at large SZA.

The variations of the ratio of UV-A/UV-B irradiance, retrieved from the spectra, were investigated. Also the covariation of the narrowband $306 \mathrm{~nm}$ irradiance and the irradiance integrated over the whole UV-B range was studied. The biases between the UV-A/UV-B irradiances calculated by means of the LibRadtran package and measured with the AvaSpec were small at SZA below $70^{\circ}$. At larger SZA the values of the ratio as well as the biases increased, significantly depending on total ozone.
\end{abstract}

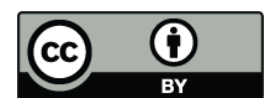

Correspondence to: K. Eerme (kalju@aai.ee)

\section{Introduction}

The importance of recording ground-level solar UV radiation spectra in addition to the broadband and narrowband filter instrument measurements has increased in recent decade (Seckmeyer et al., 2001; WMO, 2007). It is related to the deepened research of the health effects of UV radiation (Berwick and Kesler, 2005; Lehmann, 2005; Grant et al., 2005) as well as of its environmental effects in the atmosphere (Brönnimann et al., 2001), in plants and microorganisms (Neale et al., 2007; Sullivan et al., 2007). International collaboration has widened in the recent decades. The European Database for UV Climatology and Evaluation (EDUCE) stores the available UV spectra (http://www.muk.uni-hannover.de/ seckmeyer/EDUCE/ database.html) for their use by the European UV community. The database was created in the first years of this century along with the quality assurance and quality control methods for spectral measurements (Gröbner et al., 2002; Gröbner et al., 2006). In most cases the Brewer spectrometers and other expensive spectrum scanning instruments are used. As an alternative, the advancement of technology has made available the compact and simple single-monochromator array spectrometers (JETI Technische Instrumente GmbH, 2005; Oliver and Moseley, 2002; Ylianttila et al., 2005). However, the limited dynamic range and intrinsic stray light problems complicate their use.

Taking into account our previous experience in exploiting such kind of instruments at Tartu Observatory (Kutser et al., 1999), a complementary metal-oxide semiconductor (CMOS) array minispectrometer AvaSpec-256, produced by Avantes Inc., was suitable for continuous field measurements in case the necessary auxiliary devices were added.

Published by Copernicus Publications on behalf of the European Geosciences Union. 


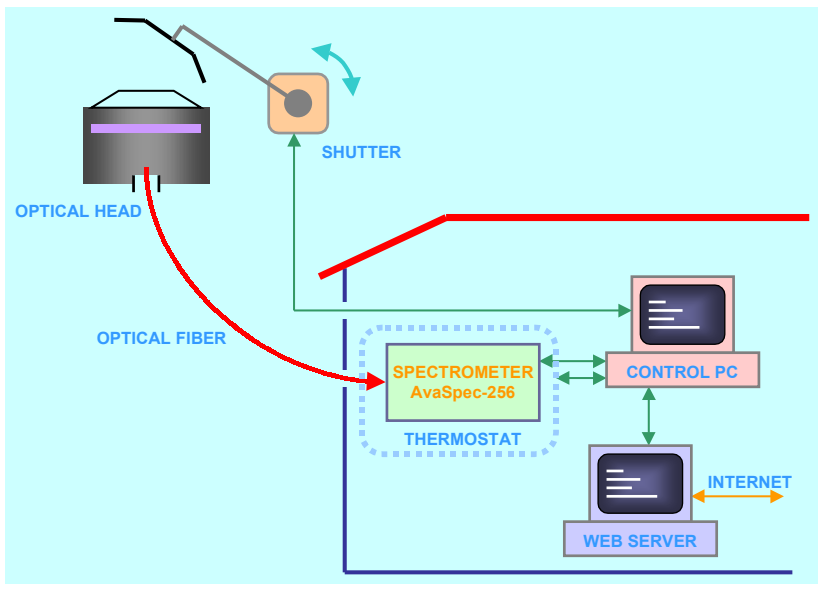

Fig. 1. Schematic diagram of the spectroradiometric system.

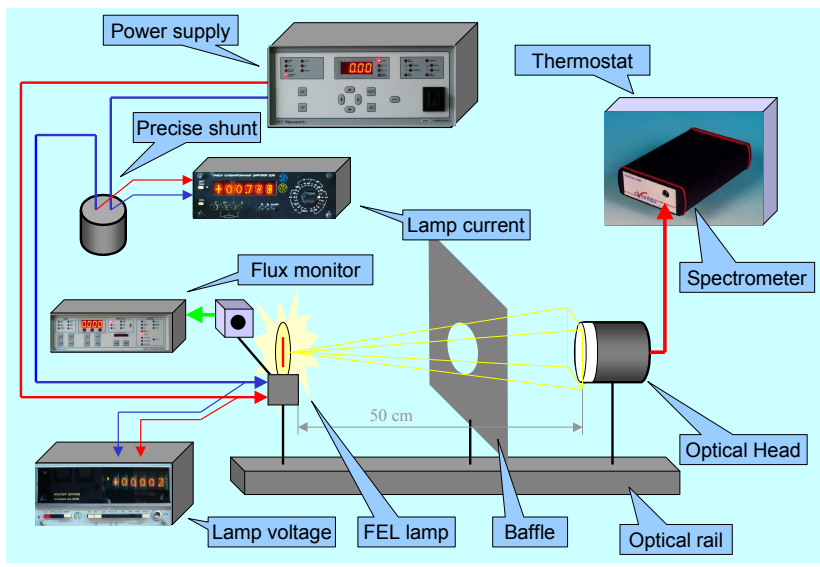

Fig. 2. Schematic setup of the sensor calibration.

Preparation of a cost-effective system to record regularly the UV spectra of solar global irradiance was started in 2004. Since 2005, the UV spectra in the wavelength range of $300-400 \mathrm{~nm}$ have been regularly recorded with a period of 15 minutes with a spectral resolution of about $1 \mathrm{~nm}$. The aim was to store the data on spectral irradiances in the local database in compliance with the EDUCE standard requirements (http://www.muk.uni-hannover.de/ seckmeyer/ EDUCE/database.html) and study the most characteristic features of spectra in different weather conditions. More than 40000 UV spectra have been recorded at the Tartu Observatory site $\left(58^{\circ} 15^{\prime} \mathrm{N}, 26^{\circ} 28^{\prime} \mathrm{E}, 70 \mathrm{~m}\right.$ a.s.l.). Located next to Tartu Observatory, Tartu-Tõravere Meteorological Station of the Estonian Meteorological and Hydrological Institute (EMHI), included since 1999 into the Baseline Surface Radiation Network (BSRN), supports the spectral measurements with the pyranometer- and pyrheliometer-measured broadband radiation data and the UV data measured by filter radiometers. All supporting meteorological information, including the aerosol optical depth (AOD) measured by the
AERONET sun photometer, direct sun total ozone and cloud data, is available from the station.

In the present paper the results of measurements of the erythemally weighted irradiances and doses of the Scintec broadband instrument UV-SET and those retrieved from spectra have been compared. Also the spectral irradiance at $306 \mathrm{~nm}$ as well as an integrated value over the wavelength region 290-315 $\mathrm{nm}$ has been compared with the narrowband spectral irradiance measured by the Kipp \& Zonen CUVB1 instrument at $306 \mathrm{~nm}$. The diurnal cycles of the ratio UVA/UV-B irradiances in sunshine and overcast conditions have been studied. The analysis of spectra recorded in situations when the solar disk is part time opened and part time obscured remains out of the scope of the present paper.

\section{Instrumentation and calibration}

\subsection{Spectrometer}

The main device in the spectrometric system is the miniature fiber optic spectrometer AvaSpec-256. The optical design of the spectrometer is based on the symmetrical CzernyTurner design with 256 pixel detector array. The CMOS detector Hamamatsu S8378-256Q is connected to an electronics board with a 14 bit AD converter and USB interface. The grating 600 lines per $\mathrm{mm}$ was selected to cover the spectral range $237-444 \mathrm{~nm}$ with blaze by $250 \mathrm{~nm}$. Entrance slit width is $50 \mu \mathrm{m}$ and the full width at half maximum (FWHM) $1 \mathrm{~nm}$. For irradiance measurements a teflon diffuser of $30 \mathrm{~mm}$ diameter and $0.4 \mathrm{~mm}$ thickness has been used as an optical input. At zenith angles above $80^{\circ}$ the actual response of the system diffuser+spectrometer was more than $20 \%$ lower than that of the cosine. At smaller zenith angles the differences did not exceed $\pm 10 \%$, mostly remaining within $\pm 5 \%$. A quartz fiber of $4 \mathrm{~m}$ length and $100 \mu \mathrm{m}$ diameter connects the optical head on the roof to the spectrometer. A Russian UFS-5 color glass filter was installed between the diffuser and fiber to reduce the visible radiation in the spectrometer and to guarantee the reliable recording of the signal in the whole UV spectral range. For reliable detection of noise level, the optical input is covered by a shutter before and after each measurement cycle.

A schematic diagram of the spectroradiometric system is presented in Fig. 1. The measurement process is fully automated. The spectra are stored in MySQL database. The control and data acquisition computer of the spectrometer is connected to the Tartu Observatory web. The measurements can be tracked by any computer of the local network. It is also possible to have access to the archive of spectra. Preliminary quality testing of the spectra is performed using the check UVspec package according to EDUCE rules (including the comparison with model calculations).

Tuning of the total responsivity by recording spectra is realized through automatic selection of integrating time within 


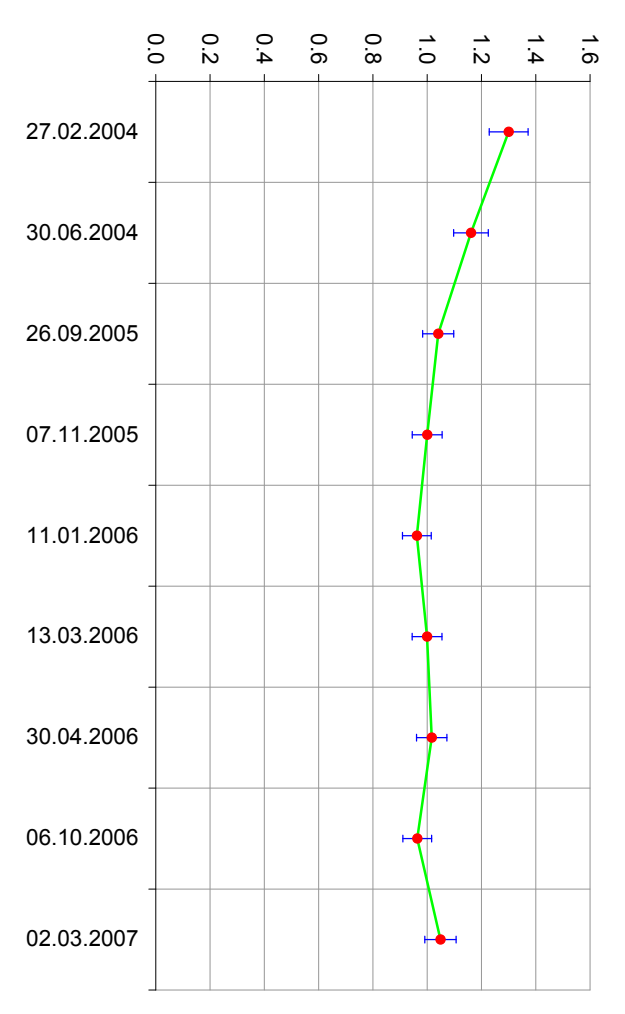

Fig. 3. Changes of the responsivity of AvaSpec-256 over time.

the interval of 1 to $60 \mathrm{~s}$. Thus a maximum value of the signal reaching approximately 16000 counts is realized for each recorded spectrum. The effective integration time can be increased by digital summing of up to 30 spectra. The temperature effects on the dark current of the sensor were significant, evoking the necessity of temperature control. The spectrometer is installed in a cooling box and kept at a constant temperature of $+7^{\circ} \mathrm{C}$ to reduce the noise level.

Calibration of UV sensors at Tartu Observatory is based on the tungsten-halogen standard lamps FEL, certificated by the Oriel company traceable to the US National Institute of Standards and Technology (NIST). A schematic setup of the sensor calibration is presented in Fig. 2. As the spectrometer's responsivity changes with time, the system needs frequent recalibration. The changes of responsivity over time of exploitation is presented in Fig. 3. The reason for the decrease of responsivity during the first year of exploitation could be caused by the condensation of water vapour on the optical surfaces within the instrument instead of decrease of the array sensitivity. The results show that after a significant drop of responsivity during the first year the variations remain within a few per cent.

The intrinsic stray-light problems limit the use of array spectrometers in the UV-B region. A program for compensatory calculation of the stray light influence was applied (Kostkowski, 1997; Brown et al., 2003; Zong et al., 2006). An example of the reduction of stray light is presented in

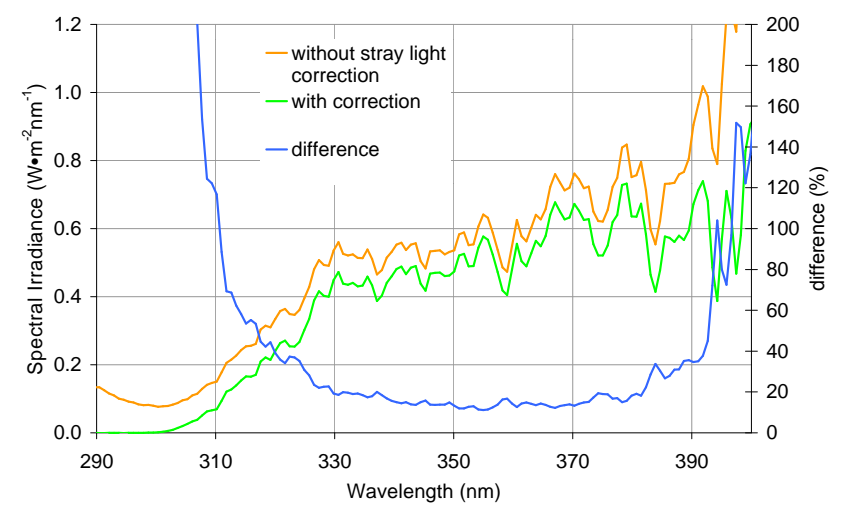

Fig. 4. Example of the stray light correction of spectra.

Fig. 4. The stray light contribution is moderate at the UVA region but increases strongly toward shorter wavelengths. Besides stray light, another strongly restricting factor in the UV-B region is a narrow dynamic range of the CMOS array. A shortwave threshold of the reliably recorded irradiance depends on the solar elevation angle and cloud cover. During midsummer noon hours it reaches $300 \mathrm{~nm}$. On clear days in midwinter the noon threshold is around $310 \mathrm{~nm}$. In midwinter overcast conditions no UV-B irradiance has been recorded in most cases. The spectral irradiance at wavelengths below $300 \mathrm{~nm}$ remains inaccessible even in the best conditions.

\subsection{Filter radiometers and auxiliary instruments}

The quantities retrieved from the spectra have been compared with these obtained by the broadband erythemally weighted Scintec sensor UV-SET and with the spectral irradiances of Kipp\&Zonen narrowband sensor CUVB1. The latter was centered at the wavelength $306 \pm 0.2 \mathrm{~nm}$ with the respective bandwidth $2 \pm 0.5 \mathrm{~nm}$. The distance between the location of the spectrometer and the filter radiometers installed at the EMHI meteorological station is about $250 \mathrm{~m}$.

The temperature of the sensor CUVB1 is stabilized at 40 ${ }^{\circ} \mathrm{C}$. The narrowband measurements of UV-B irradiance at Tartu-Tõravere Meteorological Station have been performed since February 2002. The sensor CUVB1 can be relatively easily recalibrated in units of spectral irradiance by using a standard radiation source. In 2002-2007 six calibrations of the sensor CUVB1 were performed in radiometric laboratory. The average value of the instrument's responsivity exceeded the value established by the producer only by $0.8 \%$. Taking into consideration that uncertainty of the standard lamp flux at $300 \mathrm{~nm}$ is approximately $2 \%$, we continue to use in processing of the measurement data the original value of 27.17 $\mathrm{V} /\left(\mathrm{W} \cdot \mathrm{m}^{-2} \mathrm{~nm}^{-1}\right)$.

The calibration of the Scintec UV-SET sensor is more complicated and needs a Brewer or some other good quality spectroradiometer. Our facilities do not allow to detect reliably the spectral responsivity in the range of its steep 

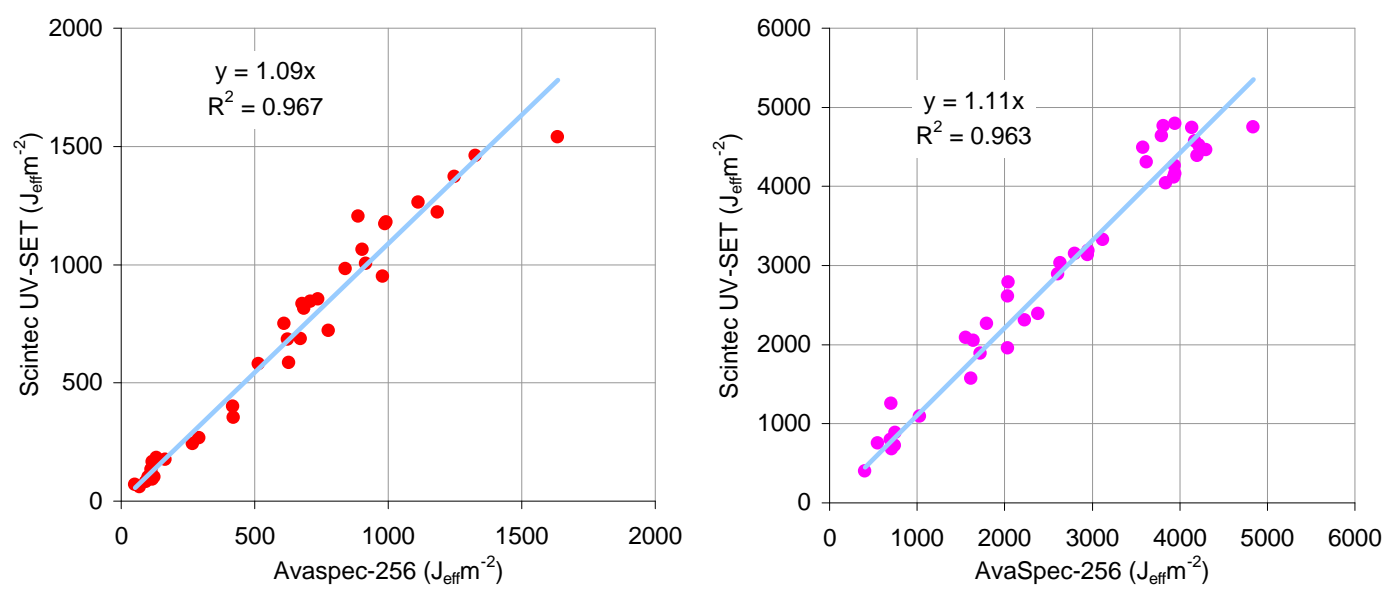

Fig. 5. Erythemal daily doses retrieved from AvaSpec-256 spectra versus Scintec UV-SET measured values in overcast (left) and sunshine (right) conditions.

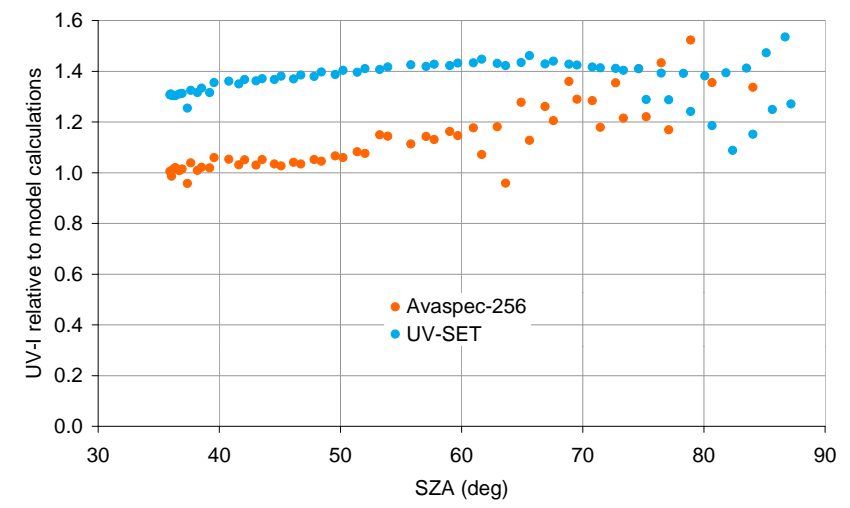

Fig. 6. Example of the ratios of the measured UV Index to the UV Index calculated using LibRadtran in clear conditions for UVSET and AvaSpec versus SZA (total ozone 373 DU, AOD at $500 \mathrm{~nm}$ $0.05)$.

decrease at the shortest wavelengths. The difference of the spectrally integrated irradiance of the UV-SET instrument from the CIE weighted response has been about $3 \%$. The total response of the UV-SET sensor has been regularly checked against the standard FEL lamp. The coefficient of radiometer response has been corrected for the decrease of total sensitivity over time, trying to maintain the initial producers calibration.

The total ozone daily values have been estimated, using the MICROTOPS-II instrument preferably during hours close to the noon; also the Earth Probe satellite TOMS and the Aura satellite OMI instrument data have been used when the local direct sun measurements were impossible. The local total ozone measurements were based on the producer calibration and the results were regularly compared with the results obtained by the OMI instrument. The average ratio of the MICROTOPS-II to OMI total ozone daily values has been 1.002 with a standard deviation of $2.3 \%$, while the extreme differences remain within $\pm 6 \%$. The AERONET Cimel-18 sun-photometer, providing the data on aerosol optical depth (AOD) in the range 340 to $1020 \mathrm{~nm}$, is also located at the EMHI meteorological station. In most cases the ratios of AOD at $340 \mathrm{~nm}$ to those at $380 \mathrm{~nm}$ and $500 \mathrm{~nm}$ occurred stable (Eerme et al., 2006). The AOD in the UV-B region was therefore expected to be proportional to the value at $340 \mathrm{~nm}$ and in agreement with that calculated using the Ångström law with average $440-870 \mathrm{~nm}$ range exponent 1 . The latter was very close to the 2002-2007 average at the study site. Reliance on the proportionality in the spectral AOD may be the reason for biases between the calculated and real spectral irradiances.

The spectral distribution of the UV irradiance is strongly influenced by cloud cover. The hourly cloud data have been detected visually at all three basic levels by the staff of the meteorological station. The cloud amounts have been recorded in tenths not in octas. A wide-angle videocamera is used beside the spectrometer for recording the current cloud situation during the measurement cycle.

\section{Comparison of spectral measurements with the filter measurements}

The primary set of quantities retrieved from the spectra contains the erythemal UV Index (UVI), spectral irradiance at $306 \mathrm{~nm}$, the integrated UV-A (the wavelengths 315$400 \mathrm{~nm}$ ) and UV-B (the wavelengths below $315 \mathrm{~nm}$ ) irradiances weighted by the rectangular boxes as well as the ratio of UV-A/UV-B. The daily doses of erythemal, $306 \mathrm{~nm}$ spectral, UV-A and UV-B irradiances are integrated, interpolating them over all the recorded spectra which satisfy the quality needs. The measurement data of the instrument CUVB1 as well as these of the erythemally weighted 


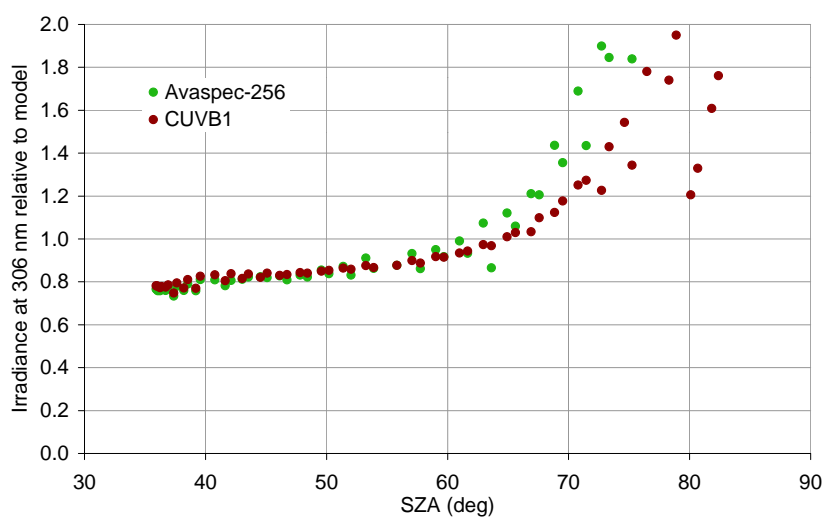

Fig. 7. Ratios of the AvaSpec-256 and the CUVB1 measured $306 \mathrm{~nm}$ spectral irradiance to the LibRadtran calculated versus SZA.

broadband instrument UV-SET have been recorded together with other radiation data with a one minute time resolution. The daily doses in $\mathrm{J} \cdot \mathrm{m}^{-2} \cdot \mathrm{nm}^{-1}$ and $\mathrm{J}_{\text {eff }} \cdot \mathrm{m}^{-2}$ have been integrated, considering all the recorded values. The weather conditions often change rapidly. During the integration of a spectrum the solar disk may be part-time cloud- free and part-time covered with clouds. As mentioned already in the Introduction, such spectra have not been considered in the present work.

The agreement of CIE weighted integrated daily doses and those recorded by the Scintec UV-SET instrument in the sunshine as well as under overcast conditions, is presented in Fig. 5. The linear correlation between the doses in both situations was 0.965 . Partly the disagreement is caused by the different temporal resolution in integration of the doses. Another reason is related to differences in angular responses of the instruments. The UVI values as well as the doses measured by the Scintec UV-SET tend to be by about $10 \%$ higher than those retrieved from spectra. The reason could be explained by the difference in irradiance scales. As noted above, the total response of the Scintec UV-SET has been regularly checked and corrected to keep the producers' scale; one cannot exclude that the latter overestimates the UVI. The results of our previous calculations of the UVI and the daily dose values performed by means of the LibRadtran package (Mayer and Kylling, 2005) also were nearly $10 \%$ lower than those measured by the UV-SET (Eerme et al., 2006). Figure 6 presents examples of the ratios of the measured UV Index to the UV Index calculated using LibRadtran. Results are shown separately for the two devices, AvaSpec and UV-SET, as a function of SZA. Measurements were done in clear-sky conditions. The bias between the UV-SET measured and retrieved from the spectra UVI reaches $30 \%$. The UV-SET ratio is more stable than the one retrieved from the spectra; however the latter is much closer to the calculated value.

The values of spectral irradiance at $306 \mathrm{~nm}$ retrieved from the spectra agreed with the CUVB1 data within $\pm 10 \%$ at

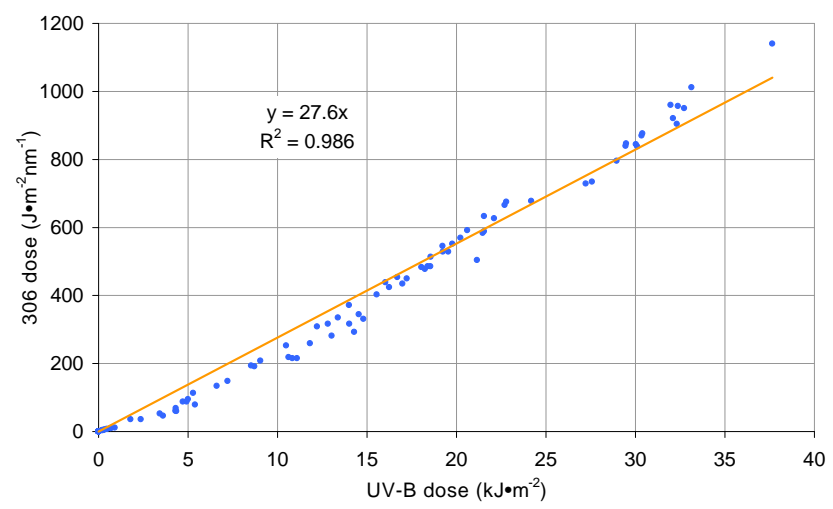

Fig. 8. Covariance of the AvaSpec-256 UV-B and narrowband filter instrument CUVB1 $306 \mathrm{~nm}$ measured spectral irradiance daily doses.

SZA values below $70^{\circ}$. The day-to-day variations of the average ratio were within a few per cent. An example of the daily cycles of both spectral irradiances relative to the calculated by means of the LibRadtran package are presented in Fig. 7. Mutual agreement between the measured values is good; the biases between the measured and calculated values, however, reach $20 \%$. The reason is not well understood yet. Significant differences between both measured values were also found at SZA above $70^{\circ}$. The linear correlation between the daily doses of irradiance in the full UV-B range and the daily doses of spectral irradiance at $306 \mathrm{~nm}$ were as high as 0.986. Their covariance is illustrated in Fig. 8. One can see that the narrowband spectral irradiance at $306 \mathrm{~nm}$ could be considered as a good proxy for the whole UV-B irradiance.

In Fig. 9 the ratios of integrated over spectra irradiances UV-A/UV-B together with the model calculated ratios versus SZA in the sunshine and small cloud amount conditions are presented for different available total ozone values in springautumnal and summer conditions. The UV-A contributions are higher at larger and lower at smaller total ozone values. At SZA below $70^{\circ}$ the biases between the calculated and measured values remained small for all total ozone values. In the SZA range of $35^{\circ}$ to $65-70^{\circ}$ the average ratio of UV-A/UV-B increases slowly from about 50 to about 100 . At larger SZA the surplus of UV-A as well as the bias between the calculated and measured value strengthens. One can see that the ratio is much larger in spring high ozone conditions (more absorptance of UV-B) than in autumnal low ozone conditions. The maximum bias between the calculated and measured values, strongly dependent on total ozone, was found at SZA around $85^{\circ}$.

\section{Conclusions}

The experience of nearly three-year-exploitation of the lowcost CMOS array minispectrometer AvaSpec-256 at Tartu 

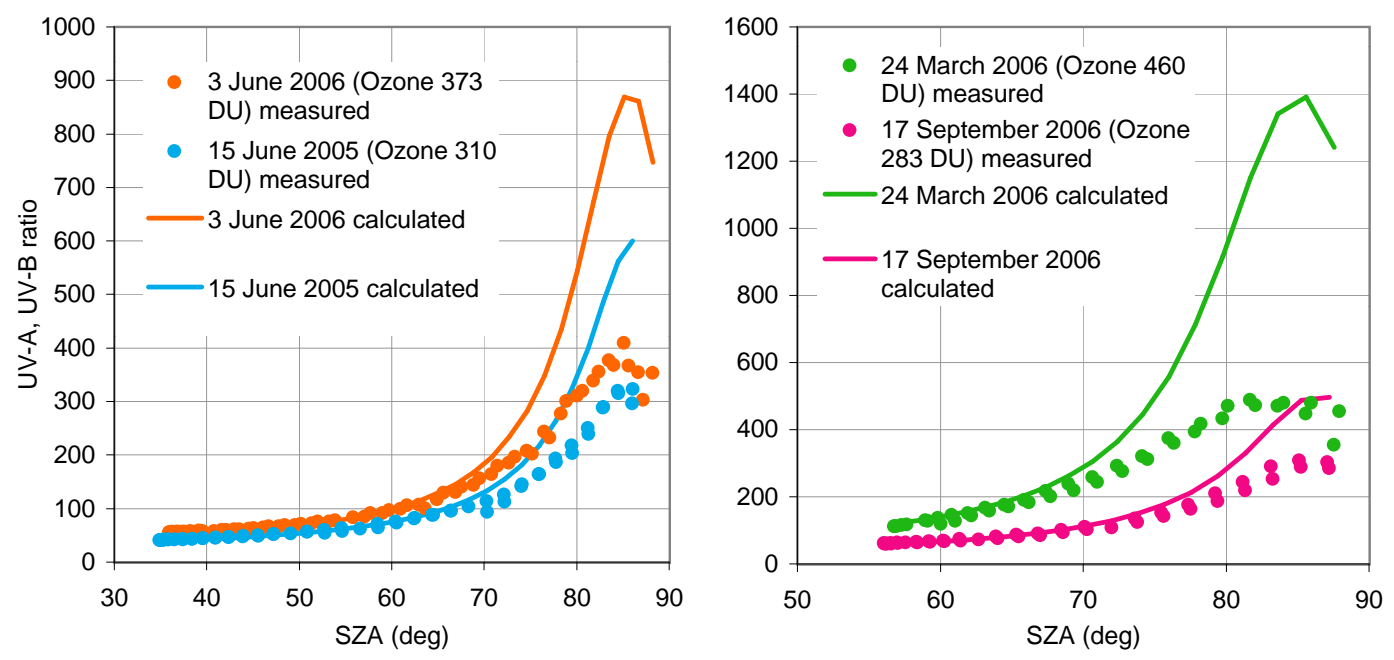

Fig. 9. Measured and calculated ratios UV-A/UV-B versus solar elevation angle in the sunshine conditions at different atmospheric total ozone values in summer (left) and spring-autumn (right).

Observatory confirms that realistic spectral distributions of global UV irradiance can be obtained. The quantities retrieved from the spectra using different weighting functions are comparable with those measured with filter instruments. The variations of the values are highly correlated. At SZA below $70-75^{\circ}$ the ratios are stable and vary within a few per cent. At larger SZA the biases grow significantly due to deviations of the instrumental angular response from the cosine law; special correction methods are necessary to increase the reliability of results.

Significant biases between the measured values and those calculated using LibRadtran codes also appear at SZA above $70-75^{\circ}$. At smaller SZA, the ratios between the values calculated and those retrieved from spectra are stable. Systematic biases between the calculated and measured quantities arising also in the case of filter instruments and reaching in some cases $20 \%$ are not well understood yet.

The agreement between the daily UV doses integrated from the spectra, recorded by the filter instruments, and by the LibRadtran codes at the study site (latitude $58.3^{\circ}$ ) in the summer half-year period is satisfactory. At the study site in the summer half-year period the integrated from the recorded spectra daily UV doses weighted by different response functions are in satisfactory agreement with the calculated values and those recorded by filter instruments. At lower latitudes the reliability of the results obtained by means of the array spectrometers should increase due to the smaller contribution of large SZA in daily doses.

Beside the cosine correction problems the major complications are related to the relatively restricted dynamic range of the instrument, the changes of responsivity over time and the stray light in the instrument. The instrument needs recalibration at least every two-three months. The stray light correction of spectra is necessary.
The shortwave threshold of reliable recording depends on solar elevation and cloudiness. At the study site it reaches the wavelength $300 \mathrm{~nm}$ in midsummer noon sunshine conditions and is limited to only $310 \mathrm{~nm}$ in noon sunshine around midwinter. In midwinter overcast conditions recording of the $\mathrm{UV}-\mathrm{B}$ radiation is quite rare.

Acknowledgements. The work has been supported by grants No 5348 and 7137 of the Estonian Science Foundation. The authors thank the Tartu-Tõravere Meteorological station of the EMHI and especially E.-M. Maasik for providing the careful measurements of total ozone.

Edited by: M. Blumthaler

\section{References}

Basics of Spectral Measurements: JETI Technische Instrumente GMBH, Jena, 47 pp., 2003.

Berwick, M. and Kesler, D.: Ultraviolet Radiation Exposure, Vitamin D and Cancer, Photochem. Photobiol., 81, 1261-1266, 2005.

Brown, S. W., Johnson, B. C., Freinholz, M. E., Yarbrough, M. A., Flora, S. J., Lykke, K. R., and Clark, D. K.: Stray-light correction algorithm for spectrographs, Metrologia, 40, 581-584, 2003.

Brönnimann, S., Eugster, W., and Wanner, H.: Photo-oxidant chemistry in the polluted boundary layer under changing UV-B radiation, Atmos. Environ., 35, 3789-3797, 2001.

Eerme, K., Veismann, U., and Lätt, S.: Proxy-based reconstruction of erythemal UV doses over Estonia for 1955-2004, Ann. Geophys., 24, 1767-1782, 2006, http://www.ann-geophys.net/24/1767/2006/.

Edwards, G. D. and Monks, P. S.: Performance of a singlemonochromator diode array spectrometer for the determination of actinic flux and atmospheric photolysis frequencies, J. Geophys. Res., 108, 8546, doi:10.1029/2002JD002844, 2003. 
Grant, W. B., Garland, C. F., and Holick, M. F.: Comparisons of estimated Economic Burdens due to Insufficient Solar Ultraviolet Irradiance and Vitamin D and Excess Solar UV Irradiance for the United States, Photochem. Photobiol., 81, 1276-1286, 2005.

Gröbner, J., Blumthaler, M., Kazadzis, S., Bais, A., Webb, A., Schreder, J., Seckmeyer, G., and Rembges, D.: Quality assurance of spectral solar UV measurements: results from $25 \mathrm{UV}$ monitoring sites in Europe, 2002 to 2004, Metrologia, 43, S66S71, 2006.

Gröbner, J., Rembges, D., and Bais, A.: Quality assurance of reference standards from nine European solar-ultraviolet monitoring laboratories, Appl. Optics, 41, 4278-4282, 2002.

http://www.muk.uni-hannover.de/ $\sim$ seckmeyer/EDUCE/database. html: A short and Friendly Guide (S\&FG) to the preparation of spectral irradiance data in Flextor format in readiness for submission to the European UV Database.

JETI Technische Instrumente GmbH: Basics of Spectral Measurement, 53 pp., http://www.jeti.com/down/basics/basics.pdf ,last access: 25 July 2008, Jena May 2005.

Kostkowski, H. J.: Reliable Spectroradiometry., 1 ed. Spectroradiometry Consulting, La Plata, MD, 609 pp., 1997.

Kutser, T., Veismann, U., Reinart, A., Erm, A., Herlevi, A., and Kallio, K.: Results of Light Absorption/Attenuation Measurements in Finnish and Estonian lakes in Summer 1997, Proc. Estonian Acad. Sci. Biol. Ecol., 48, 46-62, 1999.

Lehmann, B.: The Vitamin $\mathrm{D}_{3}$ Pathway in Human Skin and its Role for Regulation of Biological Processes, Photochem. Photobiol., 81, 1246-1251, 2005.

Mayer, B. and Kylling, A.: Technical note: The LibRadtran software package for radiative transfer calculations - description and examples of use, Atmos. Chem. Phys. Discuss., 5, 1319-1381, 2005, http://www.atmos-chem-phys-discuss.net/5/1319/2005/.
Neale, P. J., Helbing, E. W., and Day, T. A.: Symposium-in-Print: UV Effects in Aquatic and Terrestrial Environments Introduction, Photochem. Photobiol., 83, 775-776, 2007.

Oliver, H. and Moseley, H.: The use of diode array spectrometers for dosimetry and phototherapy, Phys. Med. Biol., 47, 44114421, 2002.

Seckmeyer, G., Bais, A., Bernhard, G., Blumthaler, M., Booth, C. R., Disterhoft, P., Eriksen, P., McKenzie, R. L., Miyauchi, M., and Roy, C.: Instruments to Measure Solar Ultraviolet Irradiance. Part 1: Spectral Instruments, in: Global Atmospheric Watch, Report No. 125, 30 pp., World Meteorological Organization, Geneva, Switzerland, 2001.

Sullivan, J. H., Gitz III, D. C., Liu-Gitz, L., Xu, C., Gao, W., and Slusser, J.: Coupling Short-Term Changes in Ambient UV-B levels with Induction of UV-Screening Compounds, Photochem. Photobiol., 83, 863-870, 2007.

WMO (World Meteorological Organization): Scientific Assessment of Ozone Depletion: 2006. Global Ozone Research and Monitoring Project - Report No. 50, 572 pp., Geneva Switzerland, 2007.

Ylianttila, L., Visuri, R., Huurto, L., and Jokela, K.: Evaluation of a Single-monochromator Diode Array Spectroradiometer for Sunbed UV-radiation Measurements, Photochem. Photobiol., 81, 333-341, 2005.

Zong, Y., Brown, S. W., Johnson, B. C., Lykke, K. R., and Ohno, Y.: Simple spectral stray light correction method for array spectroradiometers, Appl. Optics, 45, 1111-1119, 2006. 